\title{
Our Triassic Journalists
}

\section{Donald Richardson}

University of South Australia, Adelaide, Australia (retired)

\begin{abstract}
In 2000, the Australian Government amended the Copyright Act 1968 by passing the Copyright Amendment (Moral Rights). This was necessitated by disputes among producers, directors and writers of cinematographic films as to which should be accredited as 'author' of the material for copyright purposes. The Amendment provided 'moral rights' to authors of many kinds of creative works, but the formulation contained within itself the means of its own denaturation. The current research indicates that this has never been remarked upon by the Australian community with the result that the principle of the Amendment is infringed with impunity in the press very frequently.
\end{abstract}

Efforts to have this deficiency rectified have been unsuccessful so far.

Keywords: art, design, craftsmanship, moral rights, authorship, attribution, functionality

When the Adelaide press announced in mid-1919 that a memorial would be erected in the city to the late king Edward VII the city was assured that it would be made 'by one of the best men in the Empire' - but the artist was not named. Neither was he named in a meticulously detailed report of 19 June 1920, which told that the sculpture had arrived in Adelaide from London - 'in 114 packing cases' - and that the pedestal, which was being made locally, was nearing completion. However, that report did name all the local people who had worked on the pedestal's erection: the builder, the mason who cut the stone steps, the city's Supervisor of Public Buildings and the City Engineer.

The memorial - which has, in recent years, been revealed again in its true glory by the re-designing of its site on North Terrace - was unveiled by the visiting Prince of Wales. But the artist's name was still not mentioned on the invitation to the unveiling! Adelaide had to wait until the 16 July issue of The Advertiser to be informed that the sculptor was none other than Bertram Mackennal - the only Australian artist ever to be elected to the prestigious Royal Academy of Arts (RA), who, soon after the unveiling, was dubbed the country's first artist knight by the King of England (his friend!). Mackennal, who had migrated to London several years before, had made the memorial before the 1914-18 war, but - because bronze had been commandeered for the war effort - casting had to wait until 1919.

This seems to be a surprising lapse in a city that prided itself on being an outpost of European culture among the savages of The Antipodes, yet it seems to be a paradigm of the general attitude of the press to public sculpture in general and to architecture - indeed, to most visual art and design - in all Anglophone countries. Clearly, the press takes the attitude that such works are produced by queer foreigners with unpronounceable names and questionable life-styles with whom we will never have to deal again and - therefore - are peripheral to all that really matters to us. So, these works appear in our midst as if by magic, created by whom we know - and care - not, descending like the 'cargo' that the US airplanes brought to the wilds of Niu Gini during the Second World War. It is a wonder that we don't hack air-strips out of our parklands for the Super Fortresses to land on!

Of course, it has always been the practice in Europe to acknowledge the worth of artists and designers (without whose genius, skill and dedicated work the monuments and buildings would never even exist!) by naming them whenever their work is discussed or written about. It is also the established practice in specifically arts publications to give full accreditation to authors in any medium. But it has never been the practice in our newspapers. (However, this is not why it is appropriate to call our journalists 'dinosaurs'. More on this below.)

This deficiency in our wider culture was recognised by the federal government as long ago as 1983, at which time Attorney General Lionel Bowen established the Copyright Law Review Committee. He needed industry advice on a number of currently pressing issues regarding copyright law. One task the 
committee was charged with was examining whether legislative protection was needed for the 'moral rights' of authors and artists and - if so - what form such legislation should take. The nine-person committee, under the chairmanship of Mr Justice I F Sheppard, was composed of several senior legal men, a university librarian, the Managing Director of the Australian Mechanical Copyright Owners Society and an audio-visual education administrator. It did not include any authors or artists. After considering many submissions, it handed down its report in January, 1988. This recommended 'that it is innapropriate (sic) to introduce legislation to protect moral rights at this time'. It justified this opinion by saying that the committee was not convinced that there was sufficient demand from authors of copyright works, ${ }^{1}$ that - anyway - it did not consider that violations of moral rights occurred with such frequency or in such numbers to justify initiating new legislation, and that (as it put it) 'the theoretical basis for moral rights protection in a common law based system has not been identified'. The report listed a number of 'difficulties' ${ }^{2}$ and expressed concern that moral rights legislation might simply protect 'the personality of the author...rather than the property in the work'. But it did note that 'non-attribution instances are more obvious if one looks to newspapers and journals' (\#48) and it hoped that 'the position of authors and artists' would be improved by 'an education campaign that informs members of the public of the concerns of authors' - but it made no recommendation on the instigation of this campaign.

However, the committee's decision was close-run, only five of the nine members supporting the recommendation. Clearly, this was not sufficient to convince the Attorney General not to introduce legislation for moral rights and - in 2000 - the federal parliament passed the Copyright Amendment (Moral Rights) to the Copyright Act 1968. Necessitated mainly by frequent disputes over the ownership of the rights to cinematographic films between directors, producers and writers, it nevertheless propounded the three moral rights that all 'authors' of 'artistic works' (as the legal jargon has it) must have:

- the right of attribution of authorship of the artist who created the work,

- the right not to have authorship falsely attributed (i.e., not to have the work credited to someone who did not create it), and

- the right of integrity of authorship (i.e., the work must not be subjected to derogatory treatment of any sort, such as its destruction or mutilation; nor must anything occur that is 'prejudicial to the author's honour or reputation').

More specifically, s. 194(2) of the Amendment states - in relation specifically to an 'artistic work' that the 'attributable acts' are:

'(a) to reproduce the work in a material form;

'(b) to publish the work;

'(c) to exhibit the work to the public [and]

'(d) to transmit the work.'

The author's identification may be in any reasonable form (s.195) but it must 'be clear and reasonably prominent' (s.195AA). In relation to the latter, s.195AB says: 'When a literary, dramatic, musical or artistic work is reproduced in a material form...an identification of the author is taken to be reasonably prominent if it is included on each reproduction of the work...in such a way that a person acquiring the reproduction or copy will have notice of the author's identity'.

The legalistic language of the amendment bears little relationship to that used in the art and design world, but this is understandable because this world has never competently developed a lingua franca of its own terminology. For example, it has allowed the furphy to develop that it is impossible to define art - and a complete and clear understanding of what the term refers to was, of course, an absolute prerequisite for drafting any law that would relate to it! The equivocation dates back to Plato's (disputed) 4th century BC: 'then shall we set down the artists... as mimics of a copy of...virtue, or of whatever else they represent, who never get in touch with the truth' - a dispute that has never

\footnotetext{
${ }^{1}$ \#36 of the report states: 'Support for the proposed legislation has been pressed most strongly by a small number of representatives of authors (most particularly artists)' - obviously a scarcely credible group!

${ }^{2}$ For example, \#29 states: 'It needs to be recognised that the enactment of moral rights legislation will inevitably lead to litigation...'
} 
been settled to everyone's satisfaction. And the record includes near-contemporary, authoritative, but directly conflicting statements, such as Oscar Wilde's 1891: 'The artist is the creator of beautiful things' and that of Leo Tolstoy - just five years later: 'People will come to understand the meaning of art only when they cease to consider that the aim of that activity is beauty'. To William Wordsworth's much-quoted 1815 opinion that 'poetry...takes its origin from emotion recollected in tranquillity' the frequent rejoinder has been: 'that is not art: it is just what you do the day after you have had a row with your wife!' And - to cap it off - two well-publicised twentieth-century 'definitions': Canadian author, Marshall McLuhan, in 1967 - 'art is anything you can get away with', and the declaration of an alumnus of the London commercial art gallery Marlborough Fine Art Ltd - 'if it sells, it's art'. The dilemma of the legislators would have been quite complete.

The Copyright Act itself wisely avoided wandering into this territory by not attempting definitions of art or artist; instead it speaks only of 'artistic work' and 'authorship of artistic work', and the amendment follows suit. Of the latter, it says (under s.189 Definitions): 'artistic work means an artistic work in which copyright subsists'. The apparent circularity of this statement is only apparent, due to the fact that the Act had established that an artistic work is automatically copyright-protected as soon as it is made (and by whatever means it is made - provided there is sufficient original contribution by a human).

The Act had already established the three categories of material which can be termed 'artistic works':

- paintings, sculptures, drawings, engravings and photographs;

- buildings and models of buildings [and]

- works of 'artistic craftsmanship'.

A work that falls within the first two categories may be copyright protected even if it has no aesthetic appeal - a sensible position, given the parlous (and extremely unstable) state of contemporary aesthetic philosophy. It also - wisely - makes no reference to eternally-contested concepts like beauty and creativity.

Whereas 'art' in popular parlance is often taken to include music, theatre, literature and movies, that the term 'artistic work' in the amendment is code for 'visual art' is indicated by its juxtaposition to similar statements for literary work, cinematograph film, dramatic work and musical work. This is further established by 195AW (1A)(b) which refers to: 'a literary, dramatic, musical or artistic work as included in a cinematograph film'.

And the art world has never agreed on the distinction between art and two other key terms in its field: design and craft. Again, the legislation wisely avoids defining these entities - and in a similar way: instead of craft, it speaks of 'artistic craftsmanship'. Although the term is not specifically defined in the legislation itself, according to the Design and Artists Copyright Society (DACS) on-line Facts Sheet 'artistic craftsmanship' refers to 'forms of artistic expression beyond the conventions of paintings, drawings and sculptures...a category of artistic works exhibiting both artistry and craftsmanship...works such as a range of pottery, book bindings, hand painted tiles, stained glass windows, wrought-iron gates, cutlery and needlework'. Works exhibiting these qualities have been granted copyright protection in the past through precedents set in case law - so long as they display both aesthetic appeal and 'craftsmanship'. And the courts have ruled that something displays 'craftsmanship' if those who make it display skill, knowledge of materials and pride in their workmanship (however, the item must be something that is not purely functional).

The Australian Copyright Council's February, 2012, Information Sheet, 'Designs for Functional Articles', gives a brief overview of the copyright and design laws as they relate to the protection of designs for functional articles such as furniture, garden ornaments, fashion accessories, machinery, toys and home-wares. This paper correctly identifies functionality as the concept that distinguishes design from art - something the art/design world itself has so far been unable to do. Although the concept is exceedingly ancient in practice, its formulation dates only from 1896, when American architect, Louis Sullivan, coined the famous phrase, 'form follows function', maintaining that this is a law of nature which applies to human-made as well as to natural things. It has been accepted as the sine qua non of design for nearly two centuries. Now no longer are hospitals, art galleries, churches and port facilities automatically built in the form of the Greek or Roman temple, but their forms express ('follow') their functions. Good and clear examples of this 
principle in Australia are the National Art Gallery of Victoria, in Melbourne, and the Australian War Memorial, in Canberra - but not the Sydney Opera House, however much it may be admired for other reasons! ${ }^{3}$ And a further condition is always implied: the building must 'work'; i.e., it is functional.

As the Information Sheet states, works of design may be covered by design as well as copyright laws, and the two overlap in complicated ways.

In spite of all this complication, the terminology and intention of the moral rights amendment is quite clear, so one would think that the unconscionable treatment that Mackennal suffered in 1920 would now not happen. But, not so! Nearly a century later, the situation in Adelaide has not changed one iota: for example, The Advertiser frequently refers to an impressive and popular abstract, stainlesssteel sculpture that is set in the city's Rundle Mall - Two Spheres, by Herbert Flugelman (1923-2013) - only as 'Bert's Balls' and only rarely is the artist's name given. This is clearly derogatory treatment as defined in $\mathrm{s} .95 \mathrm{AK}(\mathrm{c})$ of the amendment: 'derogatory treatment, in relation to an artistic work, means: '(c) the doing of anything else in relation to the work that is prejudicial to the author's honour or reputation.'

But the problem is not confined to South Australia: it is a national one. Observant readers will confirm that the nation's newspapers breach the Act almost every day by not attributing the authorship of a photograph, a building or a work of art they reproduce. How often do we see a photograph of a business magnate posing in front of a flashy abstract or Aboriginal painting hanging in his boardroom, a fashion-model posed before one of those abstract sculptures architects sometime characterise as a 'turd on the plaza', or an 'artist's impression' of a new skyscraper apartment building when the artist or designer - without whose work the shot or advertisement would be much less appealing, if not irrelevant - is deprived of his or her due recognition ? $^{4}$

How do they get away with it? Well, unfortunately, the Act contains within itself the means of its own denaturation. It allows to offenders the defence of 'reasonableness'. S.195AR(2) lists several conditions under which it would be 'reasonable' not to identify an author without committing infringement of the right of attribution of authorship. These include obvious situations - like difficulty or expense, and whether the work was created in the course of the author's employment or under a contract for the performance of services - but concludes with the catch-all clincher: '(e) any practice, in the industry in which the work is used, that is relevant to the work or the use of the work'. So, there is no infringement of the artist's moral rights if an article follows the regular practice of publishing and there is no doubt (as the Mackennal case indicates) that it is a long-established journalistic practice for the correct attribution of artists and designers to be ignored. ${ }^{5}$

How can it be that this act can have been drafted with such a self-abnegating clause? Appeals to senior journalists who may have taken part in the discussions of the drafting of the act yielded no response, so one can only speculate at the lobbying that the dinosaurs of the profession would have incurred.

Further, the Act provides only a civil remedy, and only to individual artists (s.190). This means that full practical application awaits an artist or architect successfully suing a publisher or author for noncompliance so that the legal parameters can be established. However, this is not likely to occur in the near future, artists and architects having better things to do than taking publishers to court. And the National Association for the Visual Arts and the Arts Law Centre of Australia, both of whom lobbied for and support the moral rights legislation, say they lack the resources to do anything about the situation.

In what is, perhaps, a sad misunderstanding of the scope of the amendment, indigenous authors of artistic works frequently claim 'copyright' over certain generic, traditional aboriginal imagery. The most striking instance of this was a case before the NSW Land and Environment Court in June, 2011. A large stone sculpture Wandjina Watchers in the Whispering Stone which had been made by two white artists, Benedikt Osvath and Vesna Tenodi, had been placed in the grounds of the ModroGorje

\footnotetext{
${ }^{3}$ It is frequently praised as a 'work of art' - rather than design - for the impressive, sculptural 'shells' or 'sails' that crown its roof, but its facilities are not adequate for the staging of any major opera.

${ }^{4}$ It should be noted here that illustrations made available without charge from the Internet under creative commons licence must be duly and properly acknowledged in any reproduction.

${ }^{5}$ Of this defence, the Arts Law Centre of Australia points out that it is not applicable to false attribution.
} 
art gallery in Katoomba. Local aborigines demanded that it be removed, protesting that it breached the 'copyright' of certain aboriginal people who live in the Kimberley region of Western Australia, where the ancient imagery of this icon occurs on rock-drawings. ${ }^{6}$ Although the court ruled that the sculpture be removed due to certain planning considerations, it - validly - refused to accept the plaintiffs' claim to copyright because it is a fact that there is no copyright of any imagery of a religious nature under any Australian law. However, this intelligence has not filtered far into the aboriginal community because we still hear claims of 'copyright' over certain imagery by indigenous groups. What is puzzling is the fact that the Arts Law Centre of Australia actually gave evidence in that case to support the Kimberley aborigines' claims to have 'copyright' over the wandjina image. Apparently, the Centre was pursuing its enduring objection to what it often refers to as 'the current gaps in legal protection afforded by intellectual property laws to indigenous culture, ${ }^{7}$ but its methodology has to be questionable. Additionally, it should have been aware that moral rights can only be claimed by individuals, not groups.

Another instance in which religious imagery - this time Christian - was allegedly traduced (although copyright, as such, seems not to have been mentioned) was in the poster for the 1997 Adelaide Festival of Arts. It featured a Greek Orthodox Church icon of the Virgin Mary from whose arms the Christ Child had been removed to be replaced by a piano-accordion! Designed at the instigation of the Festival Director, Robyn Archer, it was a striking and humorously-appealing advertisement, but it was reviled by Adelaideans of various conservatively-religious persuasions. Even the then Prime Minister, John Howard, protested that it was a deliberate attempt to offend Christians!

In the meantime, busy newspaper proprietors and editors allow the inertia of past practice to flow on. And the Act is, of course, an inconvenient imposition on the kind of editor who regards illustrations merely as a decorative ornamentation to the text.

The non-recognition of artists and designers by the press is, indeed, an ancient and entrenched tradition in this country. For example, hardly any Australian community knows who designed and sculptured its war memorial. The reason for this is that there has long been a consensus that only the names of those who served and/or died in a war should appear on the relevant memorial. This means that in only the minority of cases was the sculptor permitted to sign his/her work. And - surprisingly - this convention was adopted, too, by reporters: even when the commissioning and/or unveiling of these memorials was written up in newspapers, the sculptor or architect was very rarely named. The exceptions - significant because of both their significance and their rarity - are mainly in the cases of the 'national' memorials in each of our capital cities. In Melbourne, for instance, the magnitude and significance of the Shrine of Remembrance was such that the designers (architects, Philip Hudson (1887-1952) and James Wardrop (1891-1975) and the sculptor (Paul Montford (1868-1938)) were frequently named in the many press reports of its genesis and evolution. Similarly, the South Australian National War Memorial in Adelaide, which resulted from a widely-advertised competition, gained much local press attention due to the fact that the sculptures were all designed in Sydney by the head of the sculpture department of East Sydney Technical College, George Rayner Hoff (18941937), but carved in marble in situ in Adelaide from Hoff's one-quarter-size plasters by local artisan Julius Henschke (1888-1955). (The fact that one the figures on this memorial is a female - not an idealised, classically-robed and -coiffed matron, but a short-skirted 'flapper' - inspired some slightly salacious reporting in the local papers!)

Hoff also provided the sculptures for Sydney's Anzac Memorial, which was erected in Hyde Park in 1932-34. And the designer, C Bruce Dellit (1900-42), was feted in the local press for creating the first public building in Australia in the new Art Deco style. The Australian War Memorial in Canberra, too, was newsworthy in the 1930s-1940s due to its prominent position in the developing new federal capital and the fact that the competition committee was unable to decide on a single winner, instead asking two of the finalists - John Crust (c.1885-1964) and Emil Sodersten (1899-1961) - to collaborate on it.

And the magnificent digger war memorial sculptures of Charles Web Gilbert (1867-1925) in Burnside (Adelaide) and Shepparton (Victoria) bear his signature. However, in the post-First World War

\footnotetext{
${ }^{6}$ Unfortunately, these protests were accompanied by vandalism and threats of violence to the artists and officers of the Blue Mountains Council.

${ }^{7}$ Robyn Ayres, Executive Director of the Arts Law Centre of Australia in the Centre's email newsletter of 22/6/2011.
} 
period, Gilbert was a newsworthy figure due to the memorials he had created in Villers Bretonneux (France) and Suez, and his pioneering work on the picture-models ('dioramas') that became central features of the evolving Australian War Memorial in Canberra.

Similarly, Victorian sculptor Margaret Baskerville (1861-1930) - who was famous as a pioneering woman sculptor and, hence, newsworthy - received much press attention for her memorial to the executed First World War nurse, Edith Cavell, which was erected beside Melbourne's St Kilda Road in 1926 (later moved to The Domain) and a second one placed in St Paul's Cathedral. Of course, the national contemporary outrage that the Germans would execute a nurse - who was popularly (but erroneously) believed to have been innocent of the treason of which she had been convicted contributed to this attention. And Baskerville received much favourable local publicity for her 1926 First World War memorial in Maryborough (Victoria) - a bronze digger figure which had been financed by the women of the district, who also specified that a woman artist sculpture it.

In all these cases the press attention was inspired by factors other than that the artists or designers had created significant works of art or design. In the early twentieth-century, few artists were aware of any copyright rights they may have had, so they just accepted the status quo. They knew of nothing else. Times were hard in a country that had little time for sculpture or sculptors, and they were grateful enough simply to have received their commissions.

So our journalists continue to behave as dinosaurs (- if not ostriches!). And those of us who believe in the positive value of copyright have what seems to be the immense task of persuading the industry to reverse its entrenched practice of generations. The writer's own move in this direction has been to initiate the Moral Rights Awareness Campaign. This has entailed developing documents that outline the legislation for the information of both the industry and artists/designers, and a pro forma letter that artists and designers can use to protest to the former about observed infringements. It is proposed to distribute these widely to authors, artists, designers and architects organisations and to publishers in the hope that a 'softly, softly' approach will eventually create awareness of both the moral rights of artists and the concomitant moral duties of the industry so that the legislation will soon achieve full implementation. So far, a few artist's groups have joined in this campaign and, also - significantly the Australian Institute of Architects. It has also received the in-principle support of most of the state art galleries and also of the professional organisation of the commercial art galleries - which clearly recognises that it is the interest of their business that artists' names be readily recognisable and related to their work.

It is notable that it is mainly in relation to artists and architects that infringements occur: reporting on sportspeople, actors, authors, businessmen - even criminals - always includes due acknowledgements and, in many cases, also many details of their lives and peccadillos. How equitable is this? If it is a matter of interesting lives, artists and architects are usually at least as interesting - as people - as cricketers and thieves are. So, it is more likely a matter of our general ignorance of matters aesthetic, of which journalists are a sub-class.

In-house photographers and cartoonists usually have no such attribution problems, no doubt due to the historical conditions of their employment: they have always been seen as part of the industry. Anyhow, cartoonists usually sign their works. And photographers, for their part, seem to have organised themselves industrially because their prints are usually attributed in newspapers these days. What do editors and publishers have against artists and designers then? What does it say about our national culture?

The magnitude of the task is indicated by the responses that have been received so far from journalists, editors and advertisers when confronted with their infringements of artists and designers' moral rights. Most react initially with affronted disbelief. Obviously, promulgation of the legislation in 2000 and immediately after must have been - at least - deficient. Or, perhaps it was even sabotaged by the industry itself? Did it ever receive due publicity in the newspapers?

Offenders can also protest at the legislation's 'unreasonable restriction on the freedom of the press'. But, this has to be a facile position: to require the inclusion of more, rather than less, information in an article can hardly be styled a 'restriction' - especially as the number of additional words needed to comply would be relatively infinitesimal. Anyway, many readers are keen to know who create the monuments and buildings that are the subject of these press reports.

When the Adelaide Advertiser was confronted with its unconscionable treatment of Herbert Flugelman's sculpture, it referred the complaint to its legal advisers, who simply quoted back the 
terms of s.195AR 2(e) - the 'reasonableness' and 'established practice' plea. There is no doubt that this was a legitimate, if legalistic, response; however - despite this - the intention of the legislation is clear: to honour artists and designers by giving them full acknowledgement in any writing. Although it is necessarily presented in a legal framework, it is really a matter of ethical principles. In view of this, it was thought reasonable to ask the editor to justify his position philosophically - but the request received no reply!

But, a further indication of this journal's iniquitous intent is that, on 23/11/2013, it published a commissioned critical article on the city's buildings - entitled 'Bricks and Brickbats' - from which it had edited out acknowledgements made by the writers of the article! Again, objection to this was met with silence.

On the other hand, senior management of The Australian has stated that it is taking the matter seriously.

The legislation does not specify the respondents to accusations of infringement. It is assumed that these are primarily publishers and/or authors of articles and reports, but advertisers must also be legitimate targets. And, certainly, some of those approached concur. One national real estate advertiser - of the kind that takes whole-page full-colour advertisement for multi-storeyed apartment buildings in the broadsheet newspapers (which commonly wax lyrical about the building and the estate agents, but never even name the architect!) - changed its policy when approached. However, the architect named in a subsequent advertisement was, himself, a figure of national acclaim. Others ignored the approach. However, one hopes that they will come to realise that naming the architect in an advertisement could be a good marketing support. It has to be recognised that, by the time a significant advertisement has appeared in print, a significant economic investment has been made in it and to change the art-work would be an unjustifiable expense.

Surprisingly, when one firm of architects - a firm of international practice - was apprised of the fact that its name had been omitted from a full-page advertisement for a new apartment building, it replied that it knew but it did not care about it. As it gave no reason for this attitude, one can only surmise that it was taking an economic view - i.e., that it felt it had enough patronage and did not need the publicity - or, perhaps, it just did not want to 'rock the boat' of tradition. It did not indicate whether it had given permission in writing - as the law requires - for the omission.

When the Australian Broadcasting Corporation responded to the complaint that it had screened a movie on the unveiling of a sculpture of the racehorse 'Black Caviar' without mentioning that it had even been made by a sculptor, its Legal and Business Affairs officer cited both the 'reasonableness' plea and the practice known as 'fair dealing'. However, without conceding offence, he opted to name the artist in the on-line version of the story. (Obviously, the ABC has not existed long enough to be able to claim the defence of industry practice.)

This limited success must indicate that the campaign has potential to succeed - given enough time!

The 2000 amendment has ensured that moral rights do exist in law in this country. They are not propriety rights (i.e., they cannot be sold) and they cannot be waived, except by written agreement, and this only prior to publication. And, ultimately, it is in the interests of both publishers and artists and designers that they be observed: artists depend upon the publicity their works may receive to establish their reputations and, consequently, their livelihood; publishers would do well to avoid the potential of a suit for damages over such a petty issue at some time in the future.

Writing this piece in the approach to Christmas, the author could not but reflect on the legend of Santa Claus and the anonymous elves who slave away - without attribution (!) - producing the gifts that their master delivers down the chimneys of the world on Christmas Eve. This myth is solemnly recited every year to the naïve, while those who relate it know perfectly well they are lying. But it is never openly questioned. There is a tacit agreement that, in this case, deception is not immoral rather, the reverse! And the children, for their part - through their innate rationality, eventually come to realise that it is a 'fairy story' and they grow up to repeat the process with their own children. Is this a perverse plot? Or does it mean that - in the deep, dark, reptilian remnants of our brains - lurks a 
hard-wired cargo-cult mentality? Or, perhaps, it is a profound wish to be the recipients of an 'act of God?' (If the latter, we should radically revise our opinion of the artist!)

\section{REFERENCES}

[1] Copyright Amendment (Moral Rights) Act 2000 No.159,2000 Australian Government

[2] Copyright Act 1968 Australian Government

[3] Facts Sheet Design and Artists Copyright Society https://www.dacs.org.uk/knowledgebase/ factsheets

[4] Design Objects and Copyright Australian Copyright Council Information Sheet, 2012

\section{AUTHOR'S BIOGRAPHY}

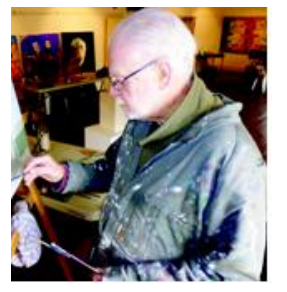

Donald Richardson is an artist and retired teacher of art and design history and theory. He was given a retrospective exhibition by the art gallery in his home town - Burnie, Tasmania - in 2016. In 2010, he was awarded the Order of Australia Medal (OAM) for services to art and the community.

Most of his several earlier books are out of print but his most recent - Creating

Remembrance. The Art and Design of Australian War Memorials - was published in 2015 by Illinios University. He is currently writing Art, Beauty and All Those Things... (for which he has no confidence in ever finding a publisher!). 